\title{
Pervasive Developmental Disorder- not Otherwise Specified: Specifying and Differentiating
}

\author{
Koray Karabekiroglu \\ Ondokuz Mayis University \\ Turkey
}

\section{Introduction}

Pervasive Developmental Disorders (PDD), also called Autism Spectrum Disorders (ASD), are defined in terms of abnormalities in social and communication development in the presence of marked repetitive behaviour and narrow interests (APA, 1994). The DSM-IV (APA, 1994) and ICD-10 (WHO, 1993) provide diagnostic criteria for autism and related disorders such as Asperger syndrome (AS), Rett's, and childhood disintegrative disorder. Unfortunately, the diagnostic category of pervasive development disorder-not otherwise specified (PDD-NOS) does not have specific criteria and is often seen as a catchall diagnosis for children who do not fit the criteria for one of the other pervasive developmental disorders (Filipek et al., 1999).

According to Cohen \& Volkmar (2005) classification systems should aim at improving communication, through their features (internal consistency, use easiness, good definition of categories) and being widely accepted. The accuracy of early diagnosis, as well as developmental pathways that are observed in young children with ASD have both theoretical and practical importance (Luyster et al., 2005). An empirically developed dimensional approach that defines the spectrum on multiple dimensions may offer several advantages. It may, for example, result in more correspondence between the results of genetic research and the phenotype of autistic disorders, provided the pathology can be summarized by empirical and valid behavior dimensions (Volkmar et al., 2004; van Lang et al., 2006; Hus et al., 2007).

It is now well recognized that children with PDD vary in the number and severity of symptoms (Szatmari et al., 2002). In DSM-IV, a diagnostic category within PDD, which is called "pervasive developmental disorder-not otherwise specified" (PDD-NOS), defines children with symptoms such as restricted social interaction, poor verbal and non-verbal communication skills, strict and/or stereotypical behaviors but without full diagnostic criteria of autism (APA, 1994). Epidemiological data suggest that PDD-NOS is at least twice as common as autism in the general community (Chakrabatri \& Fombonne, 2001). One or more of the following conditions may lead to a PDD-NOS diagnosis (1) onset of the disorder after 3 years of age, (2) atypical symptoms with regard to the 12 criteria of autism specified in DSM-IV, (3) fewer than 6 criteria and thus subtreshold (Walker et al., 2004). A categorical system like DSM-IV can be very useful for diagnosing prototypic manifestations of a disorder, but it is less useful in encompassing what may be, in its broader manifestations, a 
"spectrum disorder" (Tanguay, 2004). An assumption of the autism-spectrum model is that autism conditions lie on a continuum of social-communication skills (Baron-Cohen et al., 2001; Wakabayashi et al., 2007). A continuum view shifts us away from categorical diagnosis and towards a quantitative approach.

Diagnostic agreement for PDD-NOS is generally considered to be weak (Tanguay, 2004). Walker and colleagues presented compelling evidence, both from the literature and from their study, that attempting to improve the DSM-IV criteria for PDD-NOS can be quite frustrating (Walker et al., 2004). Many of the symptoms of PDD-NOS can occur in non-PDD conditions, such as severe mental retardation or language delay, and they may present with similar developmental history (Bishop et al., 2006). Furthermore, clinical presentation of PDD-NOS may resemble presenting symptoms in high functioning autism, Asperger's disorder, reactive attachment disorder, and psychotic disorders, and the differential diagnosis may be highly complicated.

Studies on the distinction between Autistic Disorder (AD) and Pervasive Developmental Disorder Not Otherwise Specified (PDD-NOS) have been inconclusive (Snow \& Lecavalier, 2011). The field is in need of more studies examining subtype differences. As the diagnostic validity of PDD-NOS is still open to question, and to explore proposed underlying factors, we have to assign cases based on a valid clinical assessment. Therefore, we still need to investigate further the clinical features of children with PDD-NOS that distinguish them from children with autism and other non-PDD conditions.

\section{Autism, PDD-NOS, and ADHD}

Barkley (1990) reported that it is common for children with PDD-NOS to be initially given a diagnosis of Attention Deficit/Hyperactivity Disorder (ADHD). Jensen et al., (1997) reported that $74 \%$ of the children in their study diagnosed with PDD-NOS were originally diagnosed with ADHD. Another study showed that children with PDD-NOS and ADHD did not differ from each other with respect to total number of autistic symptoms, general psychopathology, or attention difficulties (Luteijn et al., 2000). Methods for differentiating PDD-NOS from the non-PDD disorders, such as attention deficit hyperactivity disorder (ADHD), are not well established. Several investigators concluded that it is difficult to make a distinction between ADHD and PDD by using the present diagnostic criteria in DSM-IV (Bryson et al., 2008; Gökler et al., 2004). The characteristics that differentiated children with PDD-NOS from those with autism and non-PDD disorders were also explored by Buitelaar et al., (1999). Four criteria discriminated autism from PDD-NOS most effectively: children with autism more often demonstrated restricted patterns of interest, lacked varied makebelieve play, failed to use nonverbal behavior, and had an earlier age of onset. In another study (Allen et al., 2001), the PDD-NOS group (including both high- and low-functioning children) did not differ significantly from the autism or non-PDD groups on measures of language or adaptive functioning but did show less restricted stereotyped behaviors than the high-functioning autism group.

In a very recent study (Snow \& Lecavalier, 2011), authors examined the validity of PDD NOS by comparing it to autistic disorder (AD) and other developmental disorders (DD) on parent-reported behavior problems. Fifty-four children with PDD-NOS were individually matched on age and nonverbal IQ to 54 children with AD and 54 children 
with DD. The only difference between PDD-NOS and AD groups was higher scores in the PDD-NOS group on two items measuring Anxiety/Depression. Cognitive functioning may be a more salient variable than subtype when studying psychopathology in individuals with ASDs.

In a study (Karabekiroglu \& Akbas, in press) designed to explore whether PDD-NOS encompassed a distinct cluster of symptoms and clinical profile or not, we investigated differential features of PDD-NOS such as presenting symptoms, developmental history, and comorbidity with respect to autism and ADHD. The study involved 188 children (PDD-NOS $\mathrm{n}=94$; ADHD $\mathrm{n}=47$; autism $\mathrm{n}=47$ ) (male $\mathrm{n}=150$, female $\mathrm{n}=38)$ who were $5.5( \pm 2.5)$ years old on average (range 2-11 yrs.). The children with Asperger Syndrome were excluded. Preliminary PDD-NOS screening scale (PPSSS) was developed based on the 'presenting' symptoms of PDD-NOS that were systematically collected in a pilot group of children (Table 1).

The clinical diagnoses and comorbidities were based on the comprehensive mental status examination, Schedule for Affective Disorders and Schizophrenia for School Age ChildrenPresent and Lifetime Version-Turkish Version (K-SADS-PL-T), and the consensus between two child and adolescent psychiatry specialists. The prevelance rates of the most common presenting symptoms in the PDD-NOS and autism groups showed a similar pattern of distribution from most common to the least (Figure 1), even when the results were corrected for age. However, almost all of these symptoms are reported significantly less in prevalence in the PDD-NOS group.

In this study, ADHD was also explored as a co-morbid diagnosis; $38.3 \%$ of the children in the PDD-NOS group and 53.2\% of the children with autism fullfilled ADHD criteria ( $\mathrm{p}>.05)$. Compared with children in the PDD-NOS group, children in the ADHD group had significantly higher rates of co-morbid disruptive behavior disorders (27.6\% vs. 9.6\%), learning disorders $(14.9 \%$ vs. $5.3 \%)$, elimination disorders $(12.8 \%$ vs. $2.1 \%)$, tic disorders $(8.5 \%$ vs. $2.1 \%)$, social anxiety disorder $(8.5 \%$ vs. $2.1 \%)$ and lower rates of co-morbid obsessive compulsive disorder $(2.1 \%$ vs. $23.4 \%)$. The rates of other co-morbid disorders, such as depression, language disorders, and sleep disorders, were found to be similar across diagnostic groups. The findings of this study reveal that the PDD-NOS group had a high number of features in common with the autism and the ADHD groups, in terms of presenting and/or reported symptoms and developmental history. Similar to previous studies (Volkmar, et al 1993), gender distribution was similar for all groups (in each group more than $75 \%$ of the patients were male). A recent study has suggested that approximately $70 \%$ of children with ASDs have at least one comorbid psychiatric disorder (Simonoff et al., 2008). The most prevalent comorbid disorders were anxiety disorders (42\%), oppositional or conduct disorders (30\%), and ADHD (28\%).

In our study (Karabekiroglu \& Akbas, in press), as shown in Table 1 and Figure 1, the prevelance rates of the most common presenting symptoms in the PDD-NOS and autism groups had a similar pattern of distribution from more to less common. However, almost all of these symptoms were reported significantly less in children diagnosed with PDD-NOS than children with autism. The autism and the PDD-NOS shared a common clinical symptom profile on the first clinical admission. On the other hand, the children with ADHD had a distinct set of symptoms. The results suggest that PDD-NOS may be assumed as a quantitative partial subtype of autism, and it represents a less severe form that lies on a continuum of social-communication skills. 
Preliminary PDD-NOS Symptom

Screening Scale (PPSSS) Items
Presence of the symptoms (percentages)

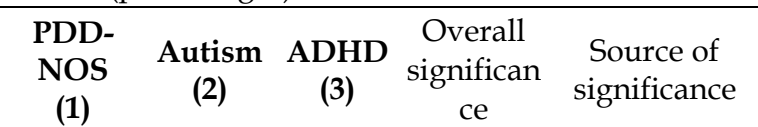
(p value)

1. poor social interaction

59.6

97.9

8.5

$<.001$

$1: 2 ; 1: 3 ; 2: 3$

2. hyperactivity

56.4

80.9

$89.4<.001$

$1: 2 ; 1: 3$

3. not speaking/ language retardation

53.2

97.9

$6.4<.001$

$1: 2 ; 1: 3 ; 2: 3$

4. aggressiveness

33.0

46.8

$61.7 \quad$ N.S.

5. stubbornness

6. inattentiveness

31.9

46.8

44.7

N.S.

$30.9 \quad 66.0$

91.5

$<.001$

$1: 2 ; 1: 3 ; 2: 3$

29.8

27.7

14.9

N.S.

$\begin{array}{llll}25.5 & 95.7 & 40.4 & <.001\end{array}$

$1: 2 ; 2: 3$

$24.5 \quad 59.6$

$6.4<.001$

$1: 2 ; 1: 3 ; 2: 3$

$23.4 \quad 48.9$

$78.7<.001$

$1: 2 ; 1: 3 ; 2: 3$ impulsiveness

11. fastidiousness, choosyness

$23.4 \quad 10.6$

22.3

14.9

10.6

N.S.

12. echolalia

20.2

46.8

$-$

N.S.

21.3

36.2

$17.0<.001$

$1: 2 ; 2: 3$

14. conduct problems

15. articulation and/or prosody problems

$18.1 \quad 8.5 \quad 4.3 \quad$ N.S.

16. lack of eye contact

14.9

59.6

14.9

8.5

14.9

10.6

17.0

$<.001$

$1: 2 ; 1: 3 ; 2: 3$

18. sleep problems

19. tactile oversensitivity

$12.8 \quad 25.5 \quad 6.4 \quad$ N.S.

25.5

17.0

N.S.

20. confusing pronouns

$11.7 \quad 12.8$

11.7

6.4

$-$

N.S.

21. shyness

22. emotional lability

23. tics

\section{7}

$-$

17.0

N.S.

10.6

4.3

27.7

$<.001$

$1: 3 ; 2: 3$

7.4

25.5

10.6

N.S.

4.3

17.0

21.3

N.S.

2.1

12.8

2.1

N.S.

$1.1 \quad 10.6 \quad 8.5 \quad$ N.S.

27. frequent startles 10.6

Table 1. Preliminary PDD-NOS Symptom Screening Scale (PPSSS) item distributions of patients in each diagnosis group 


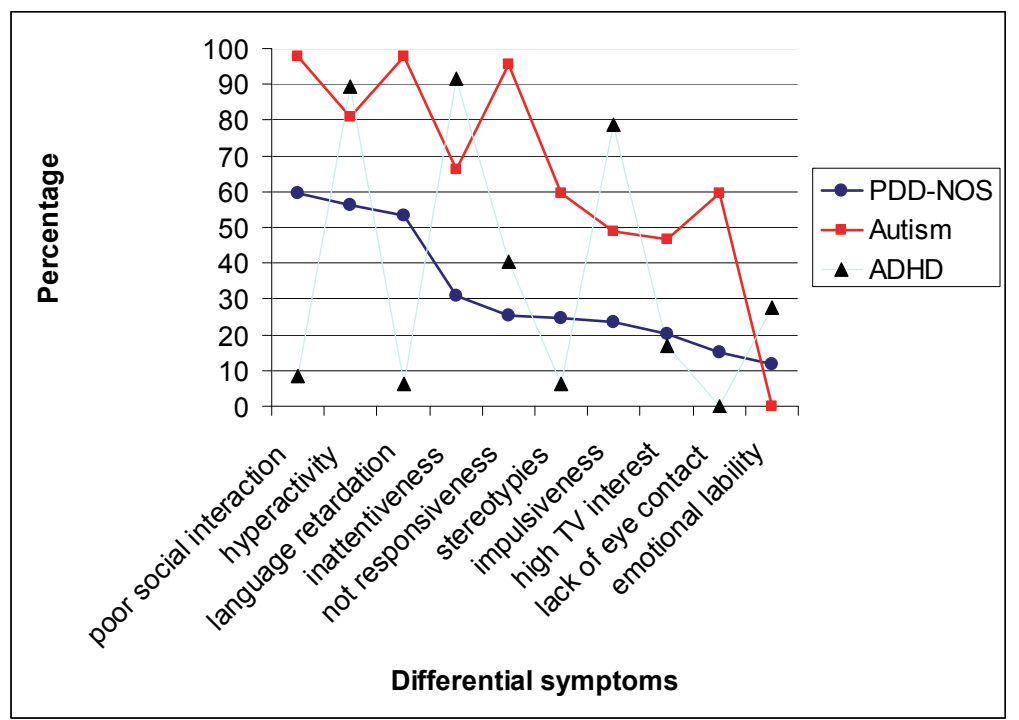

Fig. 1. The significantly discriminative symptom percentages of the diagnostic groups

\section{Cluster and factor analysis}

To identify ASD subgroups, several investigators used cluster and factor analysis based on social functioning, intelligence, developmental milestones, and so forth. Various clusters were reported (Eaves et al., 1994; Prior et al., 1998; Sevin et al., 1995; Waterhouse et al., 1996; Wing \& Gould, 1979). But these findings were not replicated and the clusters identified were not adopted or replicated in later studies. Despite several studies with ASD, clinical validity and differential features of PDD-NOS are yet to be consistently established. A very recent study (Shumway et al., 2011) examined the relationship between onset status and current functioning using a recently proposed onset classification system in 272 young children with autism spectrum disorder (ASD). Participants were classified into one of the following groups, based on parent report using the Autism Diagnostic Interview-Revised: Early Onset (symptoms by 12 months, no loss), Delay and Regression (symptoms by 12 months plus loss), Plateau (no early symptoms or loss), and Regression (no early symptoms, followed by loss). Findings indicate that current functioning does not differ according to onset pattern, calling into question the use of onset categorizations for prognostic purposes in children with ASD.

A previous study performed a factor analysis on a sample of variant categories of PDD, and two factors emerged. One factor represented autistic symptoms and another represented level of functioning (Szatmari et al., 2002). More recent studies used a factor analytic approach based on particular diagnostic instruments, such as the Autism Diagnostic Interview-Revised (ADI-R) and the Autism Diagnostic Observation Schedule (ADOS) (Tadevosyan-Layfer et al., 2003; Tanguay, 2004). The results suggested that there is a developmental continuum from affective reciprocity to emotional joint attention to verbal joint attention and to intuitive social knowledge (Tanguay, 2004). Tadevosyan-Layfer et al. (2003) found six factors: spoken language, compulsions, developmental milestones, savant skills, sensory aversion, and social intent. 
In our study (Karabekiroglu \& Akbas, in press), including all subjects in all diagnostic groups (PDD-NOS $n=94$; ADHD $n=47$; autism $n=47$ ) (male $n=150$, female $n=38$ ) who were $5.5( \pm 2.5)$ years old on average (range 2-11 yrs.), a principal axis factor analysis with Promax rotation revealed ten factors; seven were found to be discriminative (Table 2, Figure 2). We

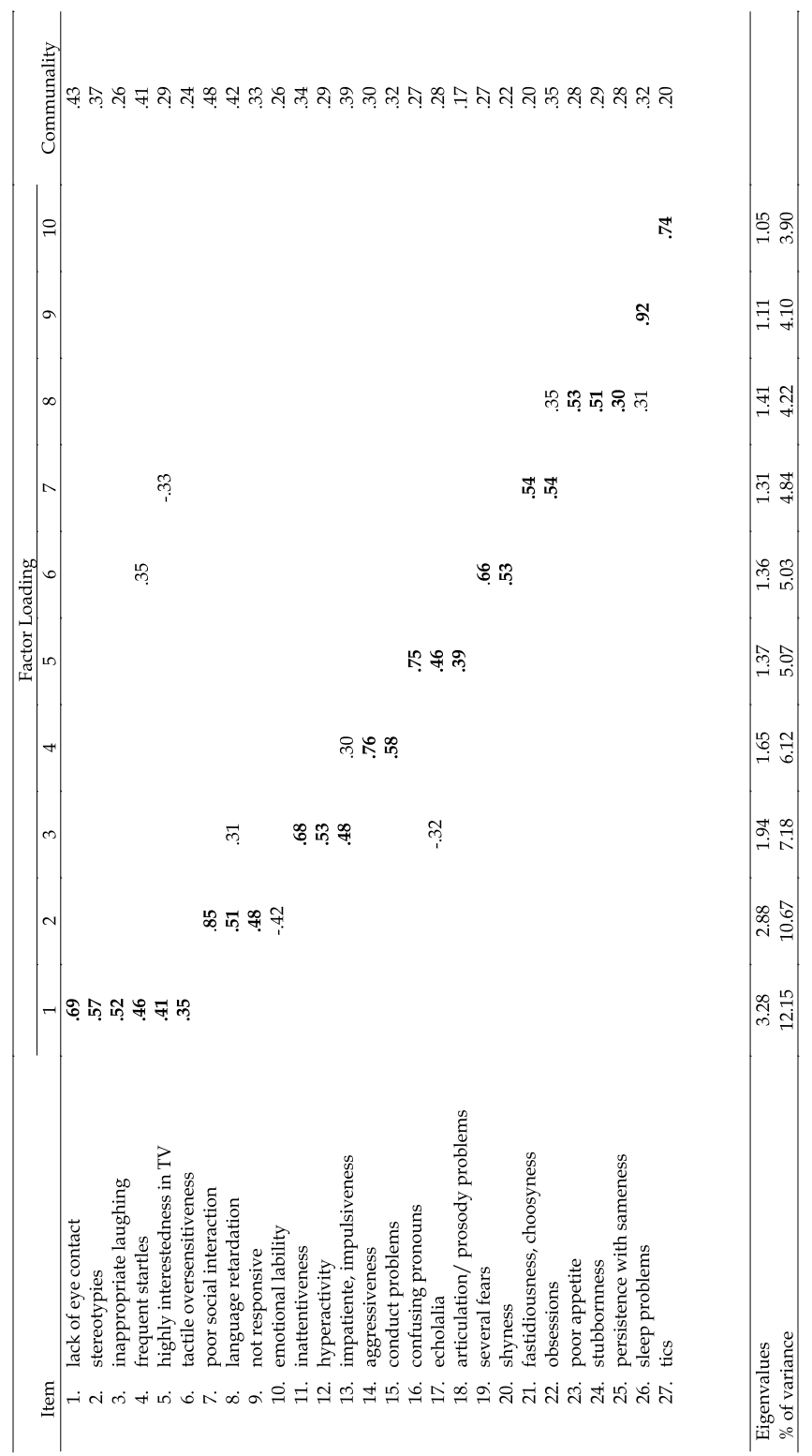

Note. Loadings $<.30$ are omitted. Adopted items into the factors are shown bold.

Table 2. PPSSS items and factor loadings for the rotated ten factors 
retained all components with eigenvalue (a measure of explained variance) greater than unity. Ten factors had eigenvalues greater than 1.0, which is a common criterion for a factor to be useful. When ten factors were requested, Kaiser-Meyer-OIkin (KMO) measure was adequate (.66), and Bartlett's Test of Spherity was significant $(\mathrm{p}<.001)$. These measures mean that the variables are correlated highly enough to provide a reasonable basis for factor analysis. We considered all variables with factor loadings 0.3 or larger in the appropriate factor matrices to define the underlying factor and we took these variables as a cluster of variables for the factor. The two rotation procedures produced similar results. When there were differences, we took the Promax solution as the preferred one. After rotation, ten factors accounted for $66.3 \%$ of the variance.

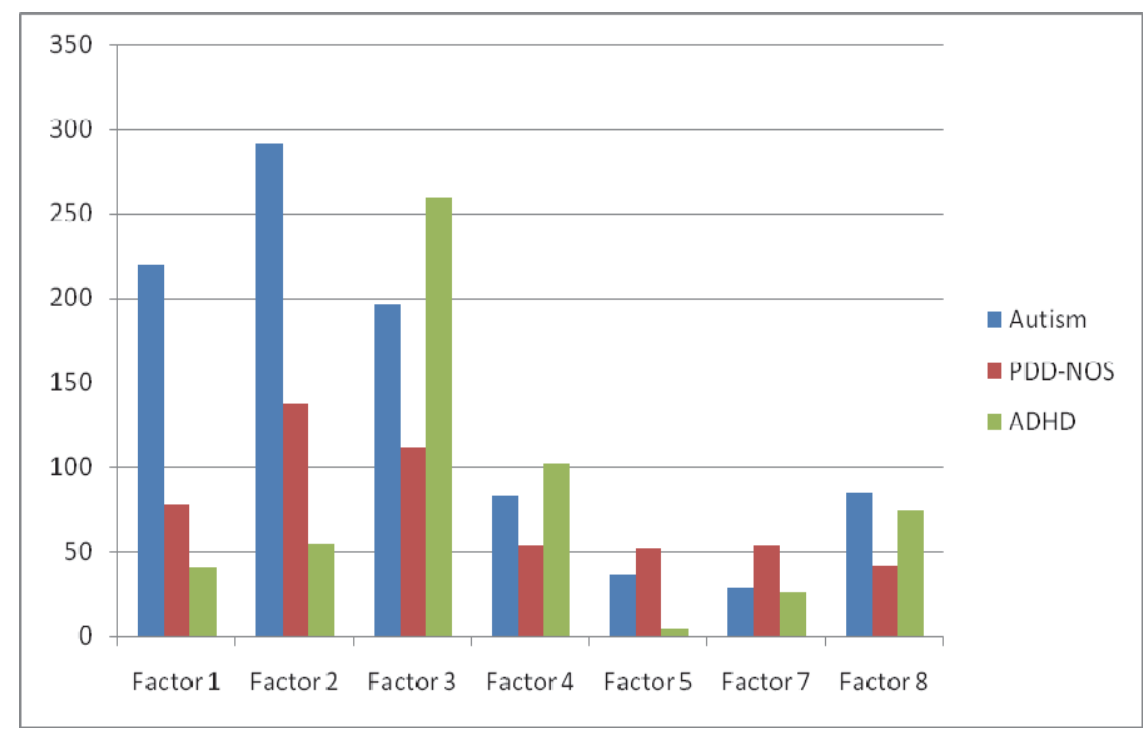

Factor 1 includes "lack of eye contact", "stereotypies", "inappropriate laughing", "frequent startles", "highly interestedness in TV", and "tactile oversensitiveness";

Factor 2 includes "poor social interaction", "language retardation", and "not responsive"

Factor 3 includes "inattentiveness", "hyperactivity", and "impatiente, impulsiveness"

Factor 4 includes "aggressiveness" and "conduct problems"

Factor 5 includes "confusing pronouns", "echolalia", and "articulation/ prosody problems"

Factor 7 includes "fastidiousness, choosiness" and "obsessions"

Factor 8 includes "poor appetite", "stubbornness", and "persistence with sameness"

Fig. 2. The significantly discriminative factors of the diagnostic groups.

We found significant differences in the toal number of symptoms between three diagnostic groups in the factors 1 ( $\mathrm{p}<.001), 2(\mathrm{p}<.001), 3(\mathrm{p}<.001), 4(\mathrm{p}=.004), 5(\mathrm{p}<.001), 7(\mathrm{p}=.026)$, and $8(\mathrm{p}=.006)$. The scores in the factors $1,2,3$, and 8 were significantly higher in the autism group compared to the PDD-NOS group. The scores in the factors 1, 2, 5, and 7 were significantly higher in the PDD-NOS group compared to the ADHD group. Inversely, the scores in the factors 3, 4, and 8 were significantly higher in the ADHD group compared to the PDD-NOS group (Figure 2). 
Based on the assumption that the items were predicted to index three constructs: symptoms related to autism, ADHD, and PDD-NOS, in a further analysis three factors were requested (Karabekiroglu \& Akbas, In press). The first factor seemed to index core autism spectrum, the second factor, disruptive behaviors spectrum, and the third factor seemed to index symptoms to be interpreted as anxiety spectrum. Four in twenty-seven items do not seem to load with any of the factors. When the total number of the symptoms in each factor were compared between the diagnostic groups, the core autism spectrum and the disruptive behavior spectrum factors revealed significant differences between the groups $(\mathrm{p}<.001)$. Post-hoc analysis showed that in the core autism spectrum factor, the autistic group had significantly more symptoms than the PDD-NOS group (4.87 vs. 2.14) ( $\mathrm{p}<.001)$, and the PDD-NOS group had significantly more symptoms than the ADHD group $(2.14$ vs. 0.81$)(\mathrm{p}<.001)$. On the other hand, on the disruptive behavior spectrum factor, both the ADHD (3.62 vs. 2.19) ( $\mathrm{p}<.001)$ and the autistic groups $(4.55$ vs. 2.19$)(\mathrm{p}<.001)$ had significantly more symptoms than the PDD-NOS group. The anxiety spectrum factor did not reveal a significant difference between diagnostic groups.

\section{Discussion}

Because the diagnostic agreement for PDD-NOS was generally considered to be weak (Tanguay 2004, Walker et al. 2004), and differentiation of PDD-NOS from the non-PDD disorders, such as ADHD was not well-defined, we conducted a factor analysis including the data from all three diagnosis groups (Autism, PDD-NOS, and ADHD) (Karabekiroglu \& akbas, in press). A factor analysis revealed three symptom clusters, core autistic spectrum, disruptive behavior spectrum, and anxiety spectrum. As would be expected, the children with autism had higher rates of symptoms in the autistic spectrum factor and the children with ADHD had higher rates of symptoms in the disruptive behavior spectrum factor. The PDDNOS group had lower rates of symptoms on both factors.

In a recent study (Kamp-Becker et al., 2009), the dimensional structure of higher functioning autism phenotype was investigated by factor analysis. The goal of this study was to identify the degree to which early symptoms of autism (measured using the ADI-R) could be predictive of the current symptoms of autism as identified using the ADOS, the adaptive behavior scales, IQ scores and theory of mind scores. The authors reported that the social interaction and communication domains were closely related to one factor namely: Social communication. An additional factor implies anxious and compulsive behavior which is associated with current social communication functioning. Another study compared the behavioral symptomatology in 26 children and adolescents with autism and 25 children and adolescents with PDD-NOS (Pearson et al., 2006). Relative to individuals with PDD-NOS, those with autism had more symptoms of depression, social withdrawal, atypical behavior, and immature social skills, and fewer family problems. These differences remained even when group differences in intellectual ability were controlled statistically. No group differences emerged in somatization, anxiety, or hyperactivity. Their findings suggested that, although both groups demonstrated considerable evidence of behavioral and emotional problems, those with autism were at particularly high risk for co-morbid behavioral and emotional disabilities (Pearson et al., 2006).

In a recent study (Mandy et al., 2011) authors aimed, first, to improve the reliability and replicability of PDD-NOS by operationalizing its DSM-IV-TR description and, second, to test its validity through comparison with autistic disorder $(\mathrm{AD})$ and Asperger's disorder (AsD). 
In a sample of 256 young people (mean age: 9.1 years) [AD (n:97), AsD (n:93) and PDD-NOS (n:66)], groups were compared on independent measures of core PDD symptomatology, associated autistic features, and intelligence. Contrary to the assumption that PDD-NOS is heterogeneous, almost all (97\%) of those with PDD-NOS had one distinct symptom pattern, namely impairments in social reciprocity and communication, without significant repetitive and stereotyped behaviors (RSB). Compared to AD and AsD, they had comparably severe but more circumscribed social communication difficulties, with fewer non-social features of autism, such as sensory, feeding and visuo-spatial problems. These individuals appear to have a distinct variant of autism that does not merely sit at the less severe end of the same continuum of symptoms.

The symptoms of ASD may change with development (Luyster et al., 2005). PDD-NOS has been assumed significantly less stable as a diagnosis (Lord et al., 2006). In a study (Kleinman et al., 2008), 77 children received a diagnostic and developmental evaluation between 16 and 35 months and also between 42 and 82 months. Diagnoses based on clinical judgment, Childhood Autism Rating Scale, and the Autism Diagnostic Observation Schedule were stable over time. Diagnoses made using the Autism Diagnostic Interview were slightly less stable. According to clinical judgment, 15 children (19\%) moved off the autism spectrum by the second evaluation; none moved onto the spectrum. Results indicate diagnostic stability at acceptable levels for diagnoses made at age 2. Nevertheless, diagnoses of autism and PDD-NOS by experienced clinicians on the basis of multiple measures were valid and reliable over time (Lord et al., 2006). If a child is given an ASD diagnosis (either autism or PDD-NOS) at age 2 years, it is highly likely to apply at age 9, although there may be some shifting within the range of ASD diagnostic categories (Lord et al., 2006). Generally, it appears that the overall picture of development for autism and PDD-NOS is similar, with most children experiencing continued impairment. Based on these two studies, there does not appear to be evidence for qualitatively discrete groups (i.e., autism versus PDD-NOS), but differences appear to be quantitative (Lord et al., 2006; Turner, et al., 2006).

A recent meta-analysis (Rondeau et al., 2010) conducted on the eight longitudinal studies on PDD-NOS that have been published from 1996 to 2009 showed that PDD-NOS diagnosis was less stable than autistic disorder diagnosis. When established before 36 months, the overall stability rate was 35\% at 3-year follow-up. Consistent with the previous literature on the reliability of the PDD-NOS diagnosis in young children, our metaanalysis did not support the discriminant and predictive validity of this category. Thus, from a clinical standpoint, children whose PDD-NOS diagnosis was established before 36 months should be re-assessed at a later age (Rondeau et al., 2010).

Similar to previous reports (Allen et al., 2001, deBruin et al., 2006, Matson, et al., 2007, Szatmari et al. 2002), in our study (Karabekiroglu \& Akbas, in press) mental retardation was significantly more prevalent in the autism than in the PDD-NOS or ADHD groups. Several investigators suggested that exploring the presence of mental retardation may be more useful in terms of planning treatment and predicting outcome than a classification based on symptom number alone (Szatmari et al., 2002). However, IQ may be a poor measure of level of functioning, based as it is on performance in a highly artificial setting (Szatmari et al. 2002). In a study (Scheirs \& Timmers, 2009) an attempt was made to distinguish among the three groups (ADHD, PDD-NOS, and ADHD plus PDD-NOS) on the basis of intelligence (WISC-III) profiles. It was found that the PDD-NOS group had higher verbal and performance IQ's, as well as higher WISC-III index scores than the ADHD group. Subtests 
Block Design and Mazes discriminated best. It was concluded that based on intelligence scores, only PDD-NOS and ADHD emerged as distinct categories, whereas the combined diagnosis did not. Allen et al. (2001) compared 18 preschool children with PDD-NOS to 176 children with autistic disorder and 311 non-autistic children with developmental language disorders (DLD) $(\mathrm{N}=201)$ or low IQ $(\mathrm{N}=110)$. The children with PDD-NOS did not differ significantly from either the children with autism or the children with DLD in verbal and adaptive skills. They suggested that the similarity of PDD-NOS children to autistic children in maladaptive behaviors and an intermediate position between autistic and DLD groups on virtually all measures helped to explain the difficulty clinicians encounter in classifying children with PDD-NOS (Allen et al., 2001).

Rates of comorbid psychiatric conditions in children with PDD-NOS are hardly available, although these conditions are often considered as more responsive to treatment than the core symptoms of PDD-NOS (deBruin et al., 2007). In our sample (Karabekiroglu \& Akbas, in press), $53.2 \%$ of the children with PDD-NOS had at least one co-morbid psychiatric disorder, including disruptive behavior disorders (40.4\%), and anxiety disorders $(18.0 \%)$. With respect to the PDD-NOS group, the ADHD group had significantly higher rates of comorbid disruptive behavior disorders, learning disabilities, tic disorders, elimination disorders, and social anxiety disorder. On the other hand, the PDD-NOS group had significantly higher rates of co-morbid obsessive compulsive disorder with respect to the ADHD group. In a previous study, DeBurin et al. (2007) explored the comorbidity in ninetyfour children with PDD-NOS, aged 6-12 years. At least one co-morbid psychiatric disorder was present in $80.9 \%$ of the children; $61.7 \%$ had a co-morbid disruptive behavior disorder, and $55.3 \%$ fulfilled criteria of an anxiety disorder. Compared to those without co-morbid psychiatric disorders, children with a co-morbid disorder had more deficits in social communication.

\section{Conclusion}

The overall results suggest that children with PDD-NOS have a high number of common features with patients having autism and ADHD. The symptoms of all three diagnostic groups appeared to form three clusters, "autistic spectrum," "ADHD spectrum," and "anxiety spectrum." Many features including language and motor development, "presenting" and/or "reported" symptom distribution, and gender distribution were found to be similar in the PDD-NOS and the autism groups. Mental retardation rate and symptom severity (e.g., "poor social interaction", "lack of eye contact", "stereotypies") were significantly higher in the autism group with respect to the PDD-NOS group. In addition, most of the previous studies supported quantitative discrimination rather than assuming that PDD-NOS and autism are qualitatively discrete groups. Therefore, PDD-NOS may be assumed as a partial subtype of autism and that it lies on a continuum of socialcommunication skill deficits. On the other hand, some of the studies suggest that these individuals appear to have a distinct variant of autism that does not merely sit at the less severe end of the same continuum of symptoms. They emphasize that compared to other disorders in PDD category, the children diagnosed with PDD-NOS had comparably severe but more circumscribed social communication difficulties, with fewer non-social features of autism. Therefore, we still need to investigate further the clinical features of children with PDD-NOS that distinguish them from children with autism and other non-PDD conditions. 


\section{References}

Allen, D.A., Steinberg, M., Dunn, M., Fein, D., Feinstein, C., Waterhouse, L., et al. (2001). Autistic disorder versus other pervasive developmental disorders in young children: same or different? European Child and Adolescent Psychiatry, 10(1):67-78

American Psychiatric Assossiation (APA) (1994). Diagnostic and Statistical Manual of Mental Disorders, Fourth Edition. Washington DC: American Psychiatric Assossiation.

Barkley, R.A. (1990), A critique of current diagnostic criteria for attention deficit hyperactivity disorder: clinical and research implications. Journal of Developmental and Behavioral Pediatrics 11:343-352

Baron-Cohen, S., Wheelwright, S., Skinner, R., Martin, J., \& Clubley, E. (2001). The AutismSpectrum Quotient (AQ): Evidence from Asperger Syndrome/high-functioning autism, males and females, scientists and mathematicians. Journal of Autism and Developmental Disorders, 31: 5-17

Bishop, S.L., Richler, J., \& Lord, C. (2006). Association between restricted and repetitive behaviors and NVIQ in children with autism spectrum disorders. Child Neuropsychology, 12 (4-5): 247-67.

Bryson, S.A., Corrigan, S.K., McDonald, T.P., \& Holmes, C. (2008). Characteristics of children with autism spectrum disorders who received services through community mental health centers. Autism. 12(1):65-82.

Buitelaar, J.K., Van der Gaag, R., Klin, A., \& Volkmar, F. (1999), Exploring the boundaries of pervasive developmental disorder not otherwise specified: analysis of data from the DSM-IV autistic disorder field trial. Journal of Autism and Developmental Disorders, 29:33-43

Chakrabarti, S., \& Fombonne, E. (2001), Pervasive developmental disorders in preschool children. JAMA 285:3093-3099

Cohen, D.J., \& Volkmar, F.R. (2005). Autismo e disturbi generalizzati dello sviluppo Trad. It. Brescia, Vannini Editrice.

deBruin, E.I., Ferdinand, R.F., Meester, S., de Nijs, P.F. \& Verheij, F. (2007). High rates of psychiatric co-morbidity in PDD-NOS. Journal of Autism and Developmental Disorders. 37(5):877-86

deBruin, E.I., Verheij, F., \& Ferdinand, R.F. (2006). WISC-R subtest but no overall VIQ-PIQ difference in Dutch children with PDD-NOS. Journal of Abnormal Child Psychology, 34(2):263-71

Eaves, L.C., Ho, H.H., \& Eaves, D.M., (1994). Subtypes of autism by cluster analysis. Journal of Autism and Developmental Disorders, 24:3-22

Filipek, P.A., Accardo, P.J., Baranek, G.T., Cook E.H., Jr, Dawson, G., Gordon, B., et al. (1999), The screening and diagnosis of autistic spectrum disorders. Journal of Autism and Developmental Disorders 29:439-484

Gökler, B., Unal, F., Pehlivanturk, B., Cengel-Kultur, E., Akdemir, D., \& Taner, Y. (2004). Okul çağı çocukları için duygulanım bozuklukları ve şizofreni görüşme çizelgesi şimdi ve yaşam boyu şekli-Türkçe uyarlamasının geçerlik ve güvenirliği. Turkish J Child Adolesc Mental Health, 11 (3):109- 116 
Hus, V., Pickles, A., Cook, E. H., Risi, S., \& Lord, C. (2007). Using the Autism Diagnostic Interview-Revised to increase phenotypic homogeneity in genetic studies of autism. Biological Psychiatry, 61, 438-448.

Jensen,V.K., Larrieu, J.A., \& Mack, K.K. (1997), Differential diagnosis between attentiondeficit/hyperactivity disorder and pervasive developmental disorder-not otherwise specified. Clinical Pediatrics (Phila) 36:555-561

Karabekiroglu, K. \& Akbas, S. (in press). Identifying and Differentiating PDD-NOS: A Comparison with Autism and ADHD. New Symposium.

Kamp-Becker, I., Ghahreman, M., Smidt, J., \& Remschmidt, H. (2009). Dimensional Structure of the Autism Phenotype: Relations Between Early Development and Current Presentation. Journal of Autism and Developmental Disorders, 39:557-571

Kleinman, J.M., Ventola, P.E., Pandey, J., Verbalis, A.D., Barton, M., Hodgson, S., et al. (2008). Diagnostic Stability in Very Young Children with Autism Spectrum Disorders. Journal of Autism and Developmental Disorders, 38:606-615

Lord, C., Risi, S., DiLavore, P., Shulman, C., Thurm, A., \& Pickles, A., (2006). Autism from two to nine, Archives of General Psychiatry, 63(6): 694-701

Luyster, R., Richler, J., Risi, S., Hsu, W.L., Dawson, G., Bernier, R., et al. (2005). Early regression in social communication in autistic spectrum disorders: a CPEA study. Developmental Neuropsychology, 27(3):311-336

Mandy, W., Charman, T., Gilmour, J., \& Skuse, D., (2011). Toward Specifying Pervasive Developmental Disorder - Not Otherwise Specified, Autism Research 4: 1-11, 2011

Matson, J.L., Wilkins, J., Smith, K., \& Ancona, M. (2007). PDD-NOS Symptoms in Adults with Intellectual Disability: Toward an Empirically Oriented Diagnostic Model. Journal of Autism and Developmental Disorders, 38(3):530-537.

Pearson, D.A., Loveland, K.A., Lachar, D., Lane, D.M., Reddoch, S.L., Mansour, R., et al. (2006). A comparison of behavioral and emotional functioning in children and adolescents with Autistic Disorder and PDD-NOS. Child Neuropsychology. 12(45):321-33

Prior, M., Eisenmajer, R., Leekam, S., Wing, L., Gould, J., Ong, B., et al.(1998). Are there subgroups within the autistic spectrum? A cluster analysis of a group of children with autistic spectrum disorders. Journal of Child Psychology and Psychiatry, 39:893902

Rondeau, E., Klein, L.S., Masse, A., Bodeau, N., Cohen, D., Guile, J.M. (2010). Is Pervasive Developmental Disorder Not Otherwise Specified Less Stable Than Autistic Disorder? A Meta-Analysis. Journal of Autism and Developmental Disorders, Dec 14 (online)

Scheirs, J.G.M., Timmers, E.A., (2009). Differentiating Among Children with PDD-NOS, ADHD, and those with a Combined Diagnosis on the Basis of WISC-III Profiles. Journal of Autism and Developmental Disorders, 39:549-556

Sevin, J.A., Matson, J.L., Coe, D., Love, S.R., Mateses, M., \& Benavidez, D.A. (1995). Empirically derived subtypes of pervasive developmental disorder. Journal of Autism and Developmental Disorders, 25:561-578 
Simonoff, E., Pickles, A., Charman, T., Chandler, S., Loucas, T., \& Baird, G. (2008). Psychiatric disorders in children with autism spectrum disorders: Prevalence, comorbidity, and associated factors in a population derived sample. Journal of the American Academy of Child and Adolescent Psychiatry, 47, 921-929.

Snow, A.V., \& Lecavalier, L., (2011). Comparing Autism, PDD-NOS, and Other Developmental Disabilities on Parent-Reported Behavior Problems: Little Evidence for ASD Subtype Validity. Journal of Autism and Develeopmental Disorders, 41:302-310

Szatmari, P., Mérette, C., Bryson, S.E., Thivierge, J., Marc-Andre, R., Cayer, M., et al. (2002). Quantifying Dimensions in Autism: A Factor-Analytic Study. Journal of American Academy of Child and Adolescent Psychiatry, 41(4):467-474.

Tadevosyan-Layfer, O., Dowd, M., Mankoski, R., Winklosky, B., Putnam, S., McGrath, L., et al. (2003). A principal components analysis of the Autism Diagnostic Interview-Revised. Journal of American Academy of Child and Adolescent Psychiatry, 42:864-872.

Tanguay, P.E. (2004). Commentary: Categorical Versus Spectrum Approaches to Classification in Pervasive Developmental Disorders. Journal of American Academy of Child and Adolescent Psychiatry, 43(2):181-182.

Turner, L.M., Stone, W.L., Pozdol, S.L., \& Coonrod, E.E. (2006). Follow-up of children with autism spectrum disorders from age 2 to age 9. Autism; 10(3): 243-65.

Van Lang, N. D. J., Boomsma, A., Sytema, S., de Bildt, A. A. Kraijer, D. W., Ketelaars, C., et al. (2006). Structural equation analysis of a hypothesized symptom in the autism spectrum. Journal of Child Psychology and Psychiatry and Allied Disciplines, 47(1), 3744

Volkmar, F.R., Szatmari, P., \& Sparrow, S.S.J. (1993). Sex differences in pervasive developmental disorders. Journal of Autism and Developmental Disorders, 23(4):57991.

Volkmar, F. R., Lord, C., Bailey, A., Schultz, R. T., \& Klin, A. (2004). Autism and pervasive developmental disorders. Journal of Child Psychology and Psychiatry and Allied Disciplines, 45(1), 135-170.

Wakabayashi, A., Baron-Cohen, S., Uchiyama, T., Yoshida, Y., Tojo, Y., Kuroda, M., et al. (2007). The autism-spectrum quotient (AQ) children's version in Japan: a cross-cultural comparison. Journal of Autism and Developmental Disorders, 37(3):491-500.

Walker, D.R., Thompson, A., Zwaigenbaum, L., Goldberg, J., Bryson, S.E., Mahoney, W.J., et al. (2004). Specifying PDD-NOS: A Comparison of PDD-NOS, Asperger Syndrome, and Autism. Journal of American Academy of Child and Adolescent Psychiatry, 43:172180.

Waterhouse, L., Morris, R., Allen, D., Dunn, M., Fein, D., Feinstein, C., et al. (1996). Diagnosis and classification in autism. Journal of Autism and Developmental Disorders, 26:59-86.

Wing, L., \& Gould, J. (1979). Severe impairments of social interaction and associated abnormalities, Journal of Autism and Developmental Disorders. 9:11-29 
World Health Organization (WHO) (1993), The International Classification of Diseases and Disorders-10 (ICD-10) Classification of Mental and Behavioural Disorders: Diagnostic Criteria for Research. Geneva: World Health Organization 


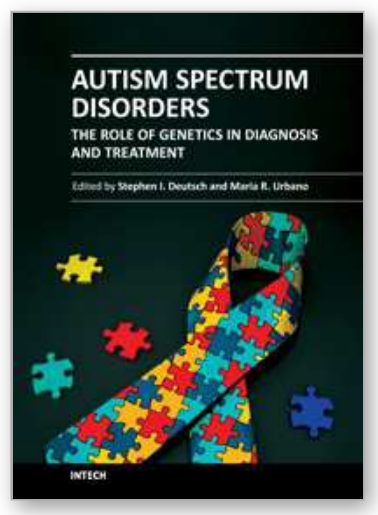

\author{
Autism Spectrum Disorders: The Role of Genetics in Diagnosis and \\ Treatment \\ Edited by Prof. Stephen Deutsch
}

ISBN 978-953-307-495-5

Hard cover, 198 pages

Publisher InTech

Published online 01, August, 2011

Published in print edition August, 2011

Estimated prevalence rates of autism spectrum disorders (ASDs) have increased at an alarming rate over the past decade; current estimates stand as high as 1 in 110 persons in the population with a higher ratio of affected males to females. In addition to their emotional impact on the affected persons and their family members (in fact, the latter are often unrecognized unaffected â€œpatientsâ€ themselves), the economic and social impacts of ASDs on society are staggering. Persons with ASDs will need interdisciplinary approaches to complex treatment and life planning, including, but not limited to, special education, speech and language therapy, vocational skills training and rehabilitation, social skills training and cognitive remediation, in addition to pharmacotherapy. The current book highlights some of the recent research on nosology, etiology, and pathophysiology. Additionally, the book touches on the implications of new research for treatment and genetic counseling. Importantly, because the field is advancing rapidly, no book can be considered the final word or finished product; thus, the availability of open access rapid publication is a mechanism that will help to assure that readers remain current and up-to-date.

\title{
How to reference
}

In order to correctly reference this scholarly work, feel free to copy and paste the following:

Koray Karabekiroglu (2011). Pervasive Developmental Disorder- not Otherwise Specified: Specifying and Differentiating, Autism Spectrum Disorders: The Role of Genetics in Diagnosis and Treatment, Prof. Stephen Deutsch (Ed.), ISBN: 978-953-307-495-5, InTech, Available from: http://www.intechopen.com/books/autismspectrum-disorders-the-role-of-genetics-in-diagnosis-and-treatment/pervasive-developmental-disorder-nototherwise-specified-specifying-and-differentiating

\section{INTECH}

open science / open minds

\author{
InTech Europe \\ University Campus STeP Ri \\ Slavka Krautzeka 83/A \\ 51000 Rijeka, Croatia \\ Phone: +385 (51) 770447 \\ Fax: +385 (51) 686166 \\ www.intechopen.com
}

\author{
InTech China \\ Unit 405, Office Block, Hotel Equatorial Shanghai \\ No.65, Yan An Road (West), Shanghai, 200040, China \\ 中国上海市延安西路65号上海国际贵都大饭店办公楼405单元 \\ Phone: +86-21-62489820 \\ Fax: +86-21-62489821
}


(C) 2011 The Author(s). Licensee IntechOpen. This chapter is distributed under the terms of the Creative Commons Attribution-NonCommercialShareAlike-3.0 License, which permits use, distribution and reproduction for non-commercial purposes, provided the original is properly cited and derivative works building on this content are distributed under the same license. 